\title{
Incidence of Intestinal Parasites in Government and Private School Going Children
}

\author{
Kritika Mishra ${ }^{1}$, Freeda Maharjan ${ }^{1}$, Reshma Chitrakar ${ }^{1}$, Nikita Chhetri ${ }^{1}$, Monica Shrestha ${ }^{1}$, Richa \\ Chaudhary ${ }^{1}$, Shashi Bhushan Chaturwedi ${ }^{1}$ \\ ${ }^{1}$ Department of Microbiology, DAV College, Dhobighat, Lalitpur
}

Corresponding author: Shashi Bhushan Chaturwedi, E-mail: sbhushan2016@gmail.com

\begin{abstract}
Objective: Aim to assess the incidence of intestinal parasites in government and private school going children.

Methods: The work was conducted from October, 2018 to March, 2019 at Microbiology Laboratory of DAV College, Dhobighat, Lalitpur. A total of 100 stool samples of children aged between 5-12 years were collected from both government and private schools situated in Lalitpur metropolitan city, during school hours. The stool samples were examined for intestinal parasites by Saline wet mount; Iodine wet mount and Formal-ether sedimentation technique. The questionnaires accompanying the queries related to the study were filled.
\end{abstract}

Results: Of the total 100 stool samples examined, intestinal parasites were observed in $7 \%(7 / 100)$ of the total stool samples. Among the positive stool samples, $71 \%(5 / 7)$ of the stool samples were from government school's children whereas $29 \%$ (2/7) were from private school's children. Fifty seven pecentage $57 \%(4 / 7)$ girls and $43 \%(3 / 7)$ boys were found to be infected with intestinal parasite in the tested stool samples. Out of total parasite detected, 57\% (4/7) were eggs of Ancylostoma duodenale, $29 \%$ (2/7) were eggs of Ascaris lumbricoides and 14\% (1/7) were cysts of Giardia lamblia. The study indicates that Ancylostoma is the most commonly infecting parasite followed by Ascaris and Giardia.

Conclusion: Personal hygiene and sanitary condition were responsible for the incidence of intestinal parasites in the school going children. Environmental sanitation improvement and health education promotion will be helpful to reduce the parasitic infection rate.

Keywords: Intestinal parasites, Samples, Sedimentation, Sanitation, Infection

\section{INTRODUCTION}

Parasites are those organisms which receive nourishment and shelter from another organism where they live, and host is the organism which harbours the parasites (Chatterjee 1998). Those parasites which live on the intestine of host are known as intestinal parasites. Intestinal parasite ranges from virus, bacteria and protozoa to helminthes (Chandrasekhar et al. 2005). It is estimated that some 3.5 billion people are affected and 450 million are ill as a result of intestinal parasitic infections (Tandukar et al. 2015). Of those 450 million, at least $50 \%$ is school going children. These infections are most prevalent in tropical and subtropical regions

Date of Submission: September 8, 2020

Published Online: December, 2020 of the developing world where adequate water and sanitation facilities are lacking (Haque 2007). Children are the most affected due to heavy infections they harbor and because of their vulnerability to nutritional deficiencies. The distribution and prevalence of the various intestinal parasites species depend on sociogeographical, economical and inhabitant customs (Tandukar et al. 2015). In Nepal, 50\% of diarrheal diseases among children are due to parasites, and hence parasitic diarrhea being major killer of Nepalese children. The prevalence ranges from $32.6 \%$ to $72.4 \%$ among school going children, suggested by majority of studies done in Kathmandu and rural hills (Tandukar 
et al. 2015). Most common intestinal parasites reported from the stools of school going children in Nepal are Ascaris lumbricoides, Hymenolepis nana, hookworm, Trichuris trichiura, Giardia lambia, Entamoeba histolytica. Of the protozoal infections, amoebiasis and giardiasis are frequently reported. About $70 \%$ of health problems are due to infectious diseases. Diarrheal disease is one the major cause for morbidity and mortality in Nepal (Yadav and Prakash 2016).

Available prevalence data on parasitic infections in the developing countries of the South-east Asian regions including Nepal are not sufficient. The present study is thus conducted to compare the intestinal parasitic status among the government and private schools going children and figure out the relation between incidence based on the hygiene practices and economic status.

\section{MATERIALS AND METHODS}

A cross-sectional study was carried out among the school going children of one government school and one private school, of both genders, belonging to age group 5-12 years. A total of 100 stool samples, 50 male and 50 female stool students were taken and processed for the detection of parasites from October, 2018 to March, 2019 at microbiology laboratory of DAV College, Dhobighat, Lalitpur. Unlabeled samples or sample contaminated with urine were excluded.

Fecal samples were collected in dry, clean, leak-proof, screw-capped plastic containers and the children were asked to fill up a questionnaire with the help of their teachers and parents. From the questionnaire, major information like age of child, sex of child, family size, parent's occupation, source of drinking water at home, hand washing habit, medical complications, history of taking anti parasitic drug in last six months etc. were collected. Microscopic examination was done by normal saline and iodine wet mount method and concentration was done by formalin-ether concentration technique. Thus obtained data from laboratory examinations and questionnaire were analyzed and presented.

\section{RESULTS}

The incidence rate of the intestinal parasites among tested stool samples of school going children was found to be $7 \%(7 / 100)$. Out of $7 \%$ positive stool samples, $71.42 \%(5 / 7)$ parasites were found in students studying in government school and $28.57 \%$ (2/7) parasites were found in students studying in private school. Among detected parasites, helminthes 85.7\% (6/7) were dominated over protozoans $14.2 \%(1 / 7)$. Where, $57.17 \%(4 / 7)$ positive stool samples were detected with Ancylostoma duodenale 28.58\% (2/7) with Ascaris lumbricoides and $14.28 \%(1 / 7)$ with Giardia lamblia. Among 50 samples from males students, 6\% (3/50) were found to be positive with intestinal parasites and out of 50 stool samples from female students, 8\% (4/50) were found to be positive with intestinal parasites. Among the 100 students under this study, 48 students were found to use soap and water to wash their hands after defecation, among them 2.08\% (1/48) was detected with intestinal parasites in their stool samples. Similarly, 5 students were found using ash and water to wash their hand after defecation and none of their stool samples were tested positive for intestinal parasites. Also 15 students were found using soil and water to wash their hands after defecation out of which $6.66 \%$ $(1 / 15)$ stool samples these students were found to be positive for intestinal parasites. Similarly, 32 students were found using only water to wash their hand after defecation and out of which $15.6 \%$ (5/32) stool samples were found to be positive with intestinal parasites.

\section{Cases of Infection}

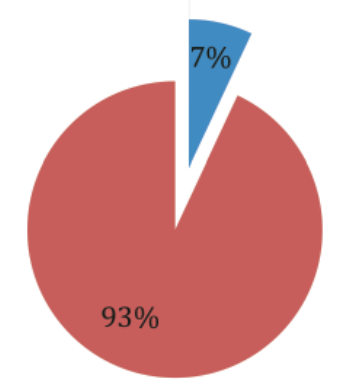

- Positive cases

negative cases

Figure 1: General incidence of intestinal parasites 
Table 1: Distribution of intestinal parasites based on type of school

\begin{tabular}{lcc}
\hline \multicolumn{1}{c}{ Schools } & Positive cases in no. & Positive Cases in \% \\
\hline Government & 5 & 71.42 \\
Private & 2 & 28.57 \\
\hline Total & 7 & 100 \\
\hline
\end{tabular}

Table 2: Incidence of type of intestinal parasite with respect to type of school

\begin{tabular}{lccc}
\hline \multirow{2}{*}{ Species of parasites identified } & \multirow{2}{*}{$\begin{array}{c}\text { Total No. of Parasite found } \\
\text { No (\%) }\end{array}$} & \multicolumn{2}{c}{ School } \\
\cline { 3 - 4 } & $4(57.17 \%)$ & $3(75 \%)$ & Government No (\%) \\
\hline Ancylostoma duodenale & $2(28.58 \%)$ & $1(50 \%)$ & $1(50 \%)$ \\
Ascaris lumbrocoides & $1(14.28 \%)$ & $1(100 \%)$ & 0 \\
\hline Giardia lamblia & $\mathbf{7 ( 7 \% )}$ & $\mathbf{5 ( 7 1 . 4 2 \% )}$ & $\mathbf{2 ( 2 8 . 5 7 \% )}$ \\
\hline Total &
\end{tabular}

Table 3: Incidence of intestinal parasites based on gender

\begin{tabular}{lcccc}
\hline Sex & Total samples examined & Total +ve cases No (\%) & Government school No (\%) & Private School No (\%) \\
\hline Male & 50 & $3(6 \%)$ & $2(66.66 \%)$ & $1(33.33 \%)$ \\
Female & 50 & $4(8 \%)$ & $3(75 \%)$ & $1(25 \%)$ \\
\hline Total & 100 & $\mathbf{7 ( 7 \% )}$ & $\mathbf{5 ( 7 1 . 4 2 \% )}$ & $\mathbf{2 ( 2 8 . 5 7 \% )}$ \\
\hline
\end{tabular}

Table 4: Incidence of intestinal parasites on the basis of hand washing material used

\begin{tabular}{lcccc}
\hline \multicolumn{1}{c}{ Agent } & Observation no. & + ve Cases No (\%) & Government School No (\%) & Private School No (\%) \\
\hline Soap and water & 48 & $1(2.08 \%)$ & $1(100 \%)$ & 0 \\
Ash and water & 5 & $0(0 \%)$ & $0(0 \%)$ & 0 \\
Soil and water & 15 & $1(6.66 \%)$ & $1(100 \%)$ & 0 \\
Only with water & 32 & $5(15.6 \%)$ & $3(60 \%)$ & $2(40 \%)$ \\
\hline Total & $\mathbf{1 0 0}$ & $\mathbf{7}$ & $\mathbf{5 ( 7 1 . 4 2 \% )}$ & $\mathbf{2 ( 2 8 . 5 7 \% )}$ \\
\hline
\end{tabular}

\section{DISCUSSION}

Despite the government policy for anti-helminthic program and health education program launched at community level, the intestinal parasitic infestation still remains the major cause of diarrheal diseases in Nepal (Sherchand et al. 2009). In the present study, the overall incidence of intestinal parasitic infection among school going children was found to be $7 \%(7 / 100)$. Our result was compared to the others research findings related to intestinal parasites in various parts of the world. A study done by Dahal et al. (2018) showed incidence of $12.4 \%$ (24/194) in Kathmandu valley, a study by Shakya et al. (2012) showed incidence of $13.9 \%$. The higher prevalence rates were reported as $31.7 \%$ and $31.13 \%$ (Kidane et al. 2014; Tiwari et al. 2013). These differences might be due to environmental, geographical, climatic conditions of the study place and the technique used for detection of parasites. The lower prevalence in this study may be due to the hygiene habits of children and also anti-helminthic drugs given to the children.

As per our study among the two categories of school going children, intestinal parasites were found more commonly in the children of government school $71.42 \%$
(5/7) showing higher incidence of intestinal parasite compared with private school going children $28.57 \%$ (2/7). In the studies conducted by Dahal et al. (2018) and Tandukar et al. (2013), the intestinal parasites were found higher in the children of government school $(66.7 \%)$ and $(73.3 \%)$ and lower in children of private school $(33.3 \%)$ and $(7.7 \%)$ respectively. Our finding is in agreement with both studies. This is possibly due to low socio-economic status of the government school children because of which they are unable to get avail the sanitary goods and products, their poor hygienic habits as they are not much aware about sanitary practices. Similarly, lack of sanitation prevailing in the school area can also be one of the reasons.

The overall incidence of intestinal parasites in this study was 7 (7\%), out of which 4 (57.17\%) were infected by Ancylostoma duodenale along with Ascaris lumricoides $2(28.58 \%)$ and with Giardia lamblia 1 (14.28\%). Out of all positive stool samples for Ancylostoma duodenale, 3 (75\%) were form government school children's stool and 1 (25\%) was from private school children's stool. Similarly, positive stool samples of Ascaris lumbricoides were $1(50 \%)$ from government school children and 
1 (50\%) from private school children's stool. Only 1 positive stool sample showed G. lamblia which was from government school going children's stool. Whereas in the study done by Dahal et al. (2018) incidence rate of the parasite was same (A. lumbricoides $8.3 \%$, Hookworm $8.3 \%)$. In the study conducted by Tandukar et al. (2015) there was no incidence of Ancylostoma duodenale but had presence of Ascaris lumbricoides 4(5.3\%) along with T. Trichuria 2(2.6\%). The incidence of hookworm was found in higher rate in comparison to other helminthes because children are mostly exposed to external environment without slippers due to which the worm infestation can take place through their feet. Similarly, hand to mouth transmission of the eggs is more common among children. These parasites were also common among children because of consumption of faecal contaminated water, lack of public awareness.

Among the 100 samples, female children had higher incidence rate of intestinal parasitic infection (8\%) than male children (4\%). This finding is similar to the finding of study conducted in Chitwan by Rai et al. (2017) in which females were more infected i.e. $24.8 \%$ female and $21.8 \%$ male. Other study conducted by Shakya et al. 2012; Bhattachan et al. 2015 also showed that females were more infected than males. The study was not in agreement with the study done by Kidane et al. (2014) (male 58.2\%; female 62.8\%) and Chandi and Lakhani (2018) (male 28.75\%; female 35.6\%). These differences indicated that the association of gender with parasitic infection differs from one community to another and might be due to socio-behavioral activities (Khanal et al. 2016). The relatively higher incidence in female children might be mainly due to the general trend in this orthodox society where females do more household and soil related works than males. This difference also could mainly be due to living conditions.

Furthermore, an important difference was observed in hand washing practice after defecation with soap and water which had $2.08 \%(1 / 48)$ incidence of intestinal parasite, followed by soil and water $6.66 \%(1 / 15)$, ash and water $0 \%(0 / 5)$, and only with water $15.6 \%(5 / 32)$. The high incidence of intestinal parasitic infection among children using only water to wash their hands after defecation might be due to the habit of handling foods and drinks with contaminated hands. A study conducted by Tandukar et al. (2013), the intestinal parasitic infection was found higher in those children who did not follow hand washing practice after defecation (47.5\%). Tandukar et al. (2013) stated that children playing in outdoor environment get in contact with parasites and not washing hands after defecation and before meal leads to the entry of parasites in the body.

\section{CONCLUSION}

The present study reveals that incidence of intestinal parasites is comparatively higher among children of government school than the children of private school. Poverty, lack of awareness, poor environmental sanitation, raw and uncooked food consuming habit and unsafe drinking water are some of the predisposing factors highlighted by this study as causes of parasitic infections. Hence, the results of this study re-emphasize the fact that intestinal parasitic infestation among school going children in the study area is mainly water-borne and are the result of poor environmental sanitation. The burden of parasitic infestations among the school children, coupled with the poor sanitary conditions in the schools, should be regarded as an issue of public health priority. This strongly supports the need for school health programs that will involve periodic deworming, health education and improvement of school sanitation.

\section{ACKNOWLEDEMENTS}

We would like to extend our sincere thanks to D.A.V. College for letting us the use of laboratory facilities needed in the accomplishment of this study. We would also like to thank teachers and students from different schools enrolled in this study for their co-operation during the collection of samples. We would also like to thank their parents for their immense support for sample collection during the study period.

\section{REFERENCES}

Bhattachan B, Pant YB, Tiwari S, Thapa Magar D, Sherchand JB, Rai G and Rai SK (2015) Intestinal parasitic infection among school children in Chitwan district of Nepal. Journal of Institute of Medicine 37(2): 79 - 84.

Chandi DH and LakhaniSJ (2018) Prevalence of Parasitic Infections among School Children in Bhaili, Durg Chhattisgarh, India. Int J CurrMicrobiol App Sci 7(9): 1919-1925.

Chandrashekhar TS, Josh HS, Gurung M, Subba SH, Rana MS and Shivananda PG (2005) Prevalance and distribution of intestinal parasitic infestations among school children in Kaski district. Western 
Nepal. J Biomed Sci 4(1): 78-82.

Chatterjee KD (1998) Protozoology, Chatterjee Medical Publishers, Calcutta:1.

Dahal C, Katwal P, Thapa A, Sharma D and Khadka R (2018) Intestinal Parasitic Infection among the school going children of Kathmandu, Nepal. TUJM 5(1):89 -96.

Haque R (2007) Human intestinal parasites. Journal of health, population, and nutrition, 25(4): 387-391.

Khanal LK, Upadhaya S, Lamichane P, Karn S, Pokhrel S and Pahwa VK (2016) Enteric parasitic infections among school children at Rupandehi. Journal of Universal College of Medical Sciences Nepal, 4(14):30-34.

Kidane E, Kebede MS and Desta M (2014) Prevalence of intestinal parasitic infections and their associations with anthropometric measurements school children in selected primary schools, Wukro Town, Eastern Tigray, Ethiopia. Int J CurrMicrobiol App Sci, 3(3):11-29.

Shakya B, Shrestha S, Madhikarmi NL and Adhikari R (2012) Intestinal parasitic infection among school children. J Nepal Health Res Counc, 10(20):193-196.
Sherchand JB, Cross JH, Jimba M, Sherchand S and Shrestha MP (1999) Study of Cyclospora cayetanesis in Health Care Facilities, Sewage Water and Green Leafy Vegetables in Nepal. Southeast Asian J Trop Med Public Health 30(1): 5863.

Tandukar S, Ansari S, Adhikari N, Shrestha A, Gautam J, Sharma B, Raj Bhandari D, Gautam S, Nepal HP and Sherchand JB (2013) Intestinal parasitosis in school children of Lalitpur district of Nepal. BMC Research Notes 6(1): 449-451.

Tandukar S, Sherchan JB, Thapa P, Malla D and Bhandari D (2015) Intestinal Parasite Infection among School Going Children in Kathmandu Valley. Austin J Pediatr. 2(2): 02-04.

Tiwari BR, Chaudhary R, Adhikari N, Jayaswal SK, Poudel TP and Rijal KR (2013) Prevalence of Intestinal Parasitic Infections among School Children of Dadeldhura District, Nepal. JHAS 3(1): 14-16.

Yadav K and Prakash S (2016) Study of Intestinal Parasitosis among School Children of Kathmandu Valley, Nepal. Asian Journal of Biomedical and Pharmaceutical Science 59(6):40-47. 